\title{
Feelings in Literature
}

\author{
Jørgen Dines Johansen
}

Published online: 17 February 2010

C The Author(s) 2010. This article is published with open access at Springerlink.com

\begin{abstract}
In this article it is argued that feelings are all important to the function of literature. In contradiction to music that is concerned with the inwardness of humankind, literature has, because of language, the capacity to create fictional worlds that in many respects are similar to and related to the life world within which we live. One of the most important reasons for our emotional engagement in literature is our empathy with others and our constant imagining and hypothesizing on possible developments in our interactions with them. Hence, we understand and engage ourselves in fictional worlds. It is further claimed and exemplified, how poetic texts are very good at rhetorically engage and manipulate our feelings. Finally, with reference to the important work of Ellen Dissanayake, it is pointed out that the first kind of communication in which we engage, that between mother and infant, is a kind of speech that positively engages the infant in a dialogue with the mother by means of poetic devices.
\end{abstract}

Keywords Feelings $\cdot$ Literature $\cdot$ Music $\cdot$ Mimesis $\cdot$ Inwardness $\cdot$ Evolution

Semiotics $\cdot$ Communication $\cdot$ Empathy $\cdot$ Prediction $\cdot$ Hypothesis-making $\cdot$ Imagination

The study of the relationship between feelings and literature is, at the moment, popular and blooming. ${ }^{1}$ The interest in this subject, it seems to me, is justified by the fact that literary discourse itself is designed to arousing and forming the feelings of the listeners and readers.

Let us, however, start out by briefly inquiring into C.S. Peirce's ideas about feelings. It is well known that Peirce has many distinctions between kinds of interpretants. Here, however, I will only mention two divisions that between the immediate, the dynamical, and the final interpretant, and that between the emotional,

\footnotetext{
${ }^{1}$ For an overview see for instance the, also in respects, excellent article "Bodily Dialogues. Indexicality of Emotions in Literary Experience" by Sirkka Knuuttila (in Ljungberg, Veivo et al. 2009).

J. D. Johansen $(\bowtie)$

University of Southern Denmark, Copenhagen, Denmark

e-mail: jdj@litcul.sdu.dk
} 
the energetic, and the logical interpretant. Further, I do not want to get lost in an attempt to point out the differences between these two classifications, they are very close, but they point to and stress different aspects of the process of interpretation. The second classification, the one between the emotional, the energetic, and the logical interpretant, highlights different kinds of mental processes. Peirce's definition of the emotional interpretant runs as follows:

The first proper significate effect of a sign is a feeling produced by it. There is almost always a feeling which we come to interpret as evidence that we comprehend the proper effect of the sign, although the foundation of truth in this is frequently very slight. This "emotional interpretant," as I call it, may amount to much more than that feeling of recognition; and in some cases, it is the only proper significate effect that the sign produces. Thus, the performance of a piece of concerted music is a sign. It conveys, and is intended to convey, the composer's musical ideas; but these usually consist merely in a series of feelings. If a sign produces any further proper significate effect, it will do so through the mediation of the emotional interpretant, and such further effect will always involve an effort. ("Pragmatism", CP 5.475, 1907)

I am not going into the distinction between immediate, dynamical, and final interpretant and that of the emotional, energetic, and logical, they are close to each other, but while the first distinction is closely related to his categories, the second is, in addition to this, also describing some aspects of mental processes. Interesting is, in my opinion, Peirce's exemplification: A performance of a piece of music is seen as a sign, and its object is, according to Peirce, the musical ideas of its composer, and, Peirce says, "usually they consist merely in a series of feelings." I am not going to directly discuss whether Peirce commits what the new critics called an intentional fallacy, although many scholars would deny the importance of the reference to the originator of the music. ${ }^{2}$

What interests me here is the coupling of a string of sounds structurally related to each other with feelings. Whereas linguistic utterances (including literature, see below) in addition to phonetic and syntactic structures have a semantic one as well, this does not seem to be the case with regard to music. Unless, of course if one would claim that there exists a kind of proto-semantics in music because its material and structural properties are encoding the feelings of the composer, as Peirce claims, and, may be more importantly, call forth a series of feelings in the audience. Obviously, there are very many difficulties with regard to this point of view. It seems to me, however, that this position reveals something important, because without some version of it, it seems, at least to me, hard to account for the doubtlessly strong emotional effect that music exercises on people. In music, we have a semiotic that lacks reference to the external world; I think program music is negligible. However, music does not lack reference, its reference, however, is the feelings that it calls forth in the listeners; its main reference is, in short, is to an inner, mental world that seems,

\footnotetext{
${ }^{2}$ The intentional fallacy was named so in the article by William K. Wimsatt, and Monroe C. Beardsley "The Intentional Fallacy." Sewanee Review, vol. 54 (1946): 468-488. Revised and republished in The Verbal Icon: Studies in the Meaning of Poetry, University of Kentucky Press, 1954: 3-18. It should be noticed that, although it is still common to subscribe to this view, it certainly has its own difficulties.
} 
in some way, to be shared by most people belonging to a given culture, although musical taste is certainly not uniform across different segments of society.

The great Hungarian literary scholar, aesthetician, and philosopher, Georg Lukàcs, believed that music is certainly mimetic, but mimetic in the second degree. He writes:

Our point of departure is the point of view, already prevailing in Greek antiquity, that the object of musical mimesis, the object imitated by music [musikalische Wiederspielung] is human inwardness [Innerlichkeit], human emotional life. [...] Immediately and originally, however, such inwardness is as a - relatively - independent sphere not present at all. It is a product of societalhistorical development of humankind. We will be able to see that its formation [Gestaltwerden] and unfolding shows a precise parallelism with the come into being and bloom of music as an independent art form. (Lukács 1963: II, 339, my translation from German)

Hence, music imitates feelings that arise through our interaction with others in the lifeworld. However, music does not represent this interaction itself neither our common lifeworld, it only represents its emotional output in the individual psyche. Lukàcs further claims that music has two primary sources, song and rhythm connected to communal work and magical evocation. In the development of the human species, he claims that music largely loses its close relation to magic and becomes a primarily aesthetic phenomenon, which is, however, still firmly related to and expressing human feelings.

One could add that the communal struggle for survival, over evolutionary time, changes the mental capacities of humankind and among these the basic emotions, although there is no agreement on what they are. ${ }^{3}$ The growing independence-over time - of man's inner world from the interactions within the common lifeworld, is certainly relative, not absolute. With regard to music, it means, however, that it awakes feelings, even if they are not warranted by real lifeworld situations. Thus, the enjoyment music offers and its obviously strong impact on the feelings of the listeners are partly due to its making possible to experience feelings change, with regard to mode and strength, according to the development of the given piece of music. Music, then, becomes, among other things, a means of getting excited about and enjoying one owns feelings without worrying about what has caused them.

\section{The Linguistic Utterance}

A linguistic utterance is in itself a result of a complex process, because it simultaneously fulfills several functions, and thus it blends, as it were, several structuring principles on line. First of all, it is formed according to the language system in question, although it may of course offend against aspects of its grammaticality. However, in addition to its linguistic structures, utterances and texts

\footnotetext{
${ }^{3}$ Ekman et. al. is close to Darwin in giving the following list of six basic emotions: anger, disgust, fear, joy, sadness, surprise, whereas Panksepp's list is shorter: expectancy, fear, rage, panic. On both lists, however, only one positive emotion is listed, but they have all survival value.
} 
are formed according to the purposes they serve and in accordance with, or as a protest against, the conventions of the discourse and genre to which they belong. Obviously, literary discourse is not the only kind of discourse designed to arouse the feelings of an audience. The uses and history of rhetoric show that working on the pathos of an audience was considered one of the most important ways of ensuring its acceptance and consequently that it prevailed.

Furthermore, classical rhetoric was traditionally divided into three branches, forensic speech devoted to establish what has happened and whether somebody is guilty or not. Deliberative speech is directed towards the future. In order to ensure the happiness of the people, or avoid unhappiness, it suggests and argues in favor of a specific course of action, i.e. it recommends some solutions to political problems rather than others. Finally, however, a third kind of speech was singled out, the epideictic, that of praise or blame. It also had, and has, mainly practical purposes such as obituary, official speeches, demonstration, and teaching. However, from a more general point of view, epideictic speech is very important because it serves to establish and confirm the values of the community. ${ }^{4}$ Epideictic speech was, however, primarily concerned with real living or deceased people (with the exception of its use in teaching how to speak). Finally it should be mentioned that although rhetoric was preoccupied with influencing what was going on in public affairs, it, nevertheless, made use of fictions. They were used and considered useful in public speeches. According to Aristotle:

Fables are suitable for public speaking, and they have this advantage that, while it is difficult to find similar things that have really happened in the past, it is easier to invent fables, for they must be invented, like comparisons, [...] (Aristotle 1926: 277, Rhet. 1394a)

Hence, what are fundamental characteristics of literature, the use of poetic devices and fiction, are also present in persuasive speech, i.e., speech whose purpose is to making the speaker's points of view accepted by the audience by working on its feelings as well as on its reasoning powers.

\section{Overdetermined Texts}

Linguistic texts are themselves always overdetermined; they are neither produced nor interpreted by using principles belonging to a single system. Semiotics is, among other things, the study of the interrelation of different systems in the production, communication, and interpretation of meaning. Concretely, different models of semiosis and of communication are attempts to highlight and relate the different factors and forces that determine the text. Famous is, for instance, the six functions model of Jakobson (emotive, phatic, conative, referential, metalinguistic, and poetic. ${ }^{5}$ In communicating

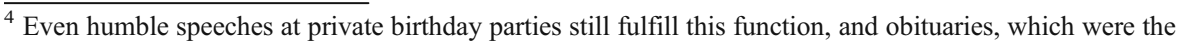
first kind of epideictic speech, in praising the achievements of the deceased, also still display and confirm the values of the community.See Perelman \& Olbrechts-Tyteca 1969: 47-54.

${ }^{5}$ ) I have myself attempted to construct Peirce's understanding of semiosis, in the so-called semiotic pyramid, I do add, however, utterer and interpreter to his triadic conception of semiosis, in order to be able to account for human communication. See, for instance Johansen 2002: 55.
} 
we always seem to do four things at the same time, namely addressing somebody, exhibiting ourselves, referring to or creating a world, and displaying the immanent patterns of the semiotic, the language in question. Obviously, these four activities are certainly not mutually exclusive. This polyfunctionality is, of course, inherited by literature. Indeed, self-expression (of the utterer), creating a virtual world, and selfrepresentation (of textual patterning) are most often fused and collaborating to heighten the expressiveness and aesthetic effect of the individual literary text, although, from the point of view of analysis, they may be distinguished.

In its world-creating capacity the literary texts represent and describe the feelings of characters and narrators. Since authors are creating narrators and characters and what is happening to them, they are able to let readers know what these creatures of their own minds, feel, and how they respond emotionally to what befalls them. Indeed, narrators, in the last analysis authors, are even able to indirectly, by showing the characters' reactions, or directly by commenting on the characters able to interpreting and explaining their emotional attitudes. In short a substantial part of the mimetic dimension of literature is concerned with the representation of feelings.

Furthermore, in representing the feelings of fictional characters, the authors are very often successful in eliciting an emotional response in the readers. Despite the fact that readers very well know that what befalls the character in a novel, never happened in the historical lifeworld, but only within a fictional world that is a product of somebody's fantasy (unless, of course, a historical character is included in the text).

One reason for such a response is, I suppose, our predisposition for empathy, our ability to feel and understand the emotional reactions of others, and to share them. Indeed, what befalls a fictional character may trigger strong reactions within a devoted readership. The case concerning the fate of the character of Little Nell in Dickens' The Old Curiosity Shop (1841) is well-known. Here a summery made by David Cody for The Victorian Web may suffice:

When The Old Curiosity Shop was approaching its emotional climax - the death of Little Nell-Dickens was inundated with letters imploring him to spare her, and felt, as he said, "the anguish unspeakable," but proceeded with the artistically necessary event. Readers were desolated. The famous actor William Macready wrote in his diary that "I have never read printed words that gave me so much pain. . . . I could not weep for some time. Sensations, sufferings have returned to me, that are terrible to awaken." Daniel O'Connell, the great Irish member of Parliament, read the account of Nell's death while he was riding on a train, burst into tears, cried "He should not have killed her," and threw the novel out of the window in despair. Even Carlyle, who had not previously succumbed to Dickens's emotional manipulation, was overcome with grief, and crowds in New York awaited a vessel newly arriving from England with shouts of "Is Little Nell dead?" (“Dickens's Popularity",The Victorian Web)

As the reaction to the fate of Little Nell should have made abundantly clear, empathy is not only a response to real people, it is easily extended to creatures that are creations of the minds of others, or of us. One reason for this is, I suppose, the role that prediction and hypothesis-making play in our interaction with others. We constantly hypothesize about how others will act in the immediate future. At least implicitly and often explicitly, we say "because this is as things are, I expect so and so to happen." Using the imagination to predicting what is going to happen next is an invaluable 
mechanism that increases our chances of survival. However, hypothesizing about future event in our lifeworld and the creation of fictional worlds are very close to each other, and hence we respond easily with empathy to emotional charged situations and events, even if they take place in an invented world.

However, the fact that what is represented never has happened and never will happen, allows us to respond more freely and in different ways to literature, because we may both have the feeling of becoming a part of its world, of participating in what is happening, and, in the next split second, we may react as outsiders who need not at all to be worried about, indeed not to care for what is happening. Oscar Wilde's reaction to the description of the death of Little Nell, whether serious or not, is also an important part of the story about its impact. He said "that no one could read the death-scene of Little Nell without dissolving into tears - of laughter." (John Cody: "Dickens' Popularity", The Victorian Web). Literature in general makes an effort to engage us in what is important to it, and it is often successful (cf. the emotional grip Dickens had on the majority of his contemporary readers). Nevertheless, it cannot command our attention and that we care for it, and this is, for two reasons, a substantial part of its attraction: First, most texts addressed to us demand that we respond, and that we often do it quickly and in prescribed or at least presupposed ways. Whether we are addressed by the authorities or by people close to us, we are obliged to act. Hence, it is a relief that we need not do so with regard to literature, and either in any prescribed way. Indeed, we may put a literary text away without bothering to finish reading it. Second, precisely because we are at liberty not to bother, the literary text must, if its author wants to be read, make up to us. Since it cannot give us orders of command, it must have some kinds of attraction in store for us such as: elaborated style, importance of subject, exiting or thrilling plot, and arousal of feelings. Still, we remain in charge, and we may respond to literature in many and complex ways and enjoy both its attempts to bind us to it and our basic liberty with regard to it. This liberty, of course, is also in force with regard to the feelings described in a literary text, we may at one moment follow the outlined path to the emotions it is supposed to arouse, and in the next distance ourselves from them.

\section{The Emotional Impact}

Here I will, however, point to another dimension of the literary text, a dimension that was briefly mentioned in the beginning with regard to music, namely the emotional impact of its material and formal properties. What distinguishes literature from most other kinds of discourse is the systematic surplus-coding of formal and material features of the sign vehicle. The point is that this surplus-coding of the expression has formative effects on the content and meaning of the literary text. I am well aware that this point has been made before, in different ways both by the Russian Formalists and by the New Critics. Indeed, the latter warned explicitly against the heresy of paraphrase. Cleanth Brooks defines what such heresy offends against:

The essential structure of a poem (as distinguished from the rational or logical structure of the 'statement' which we abstract from it) resembles that of architecture or painting: it is a pattern of resolved stresses. Or, to move closer still to poetry by considering the temporal arts, the structure of a poem 
resembles that of a ballet or musical composition. It is a pattern of resolutions and balances and harmonizations, developed through a temporal scheme.

(Brooks 1947: 203)

Brooks also compare a poem to a play in order to persuade us to see it as an action rather than as a statement. Brooks does not deny, of course, that it is possible to extract a statement from a poem, what he claims is rather that neither as structure and action it can be reduced to it. Of course, he says both poetry and drama use ideas, they are not "merely emotional." On the contrary, what he claims, is that "[ $\mathrm{t}]$ he relationship between the intellectual and the non-intellectual in a poem is actually far more intimate that the conventional accounts would represent it to be: the relationship is not that of an idea "wrapped in emotion" or a prose-sense decorated by sensuous imagery." (204)

The intimate relationship between expression and content in poetry, and in literature in general, is, I agree with Brooks, essential, and I will try to give an example to show how effectively the poeticity of a text changes its whole purport. This is my example:

What is it men in women do require?-

The lineaments of gratified desire.

What is it women do in men require?-

The lineaments of gratified desire.

(Blake 1971: 167)

Blake's little poem is certainly a show case of poetic devices; all three kinds of analogies, phonological, syntactic, and semantic and their interrelation catch and please ear and mind. And thus it is exemplary of the self-representative capacity of poetry, and of the force of analogy. At the same time, it is a poem about human desires and emotions. In fact it not only states the reciprocity of desire, it represents, even mimes it:

men : women :: women : men

This reciprocity is mimed by means of a varied repetition patterned by a consideration for rhythm and euphony (e.g. the positioning of $d o$ in lines one and three). Furthermore, the use of repetition is truly thematically significant, because it stresses the universality and reciprocity of its propositional content. The interplay between the poetic devices clearly serves the purpose of conjuring up a certain belief and a certain emotional attitude. This becomes obvious, when we use the test of paraphrase. In prose, the propositional content may be rendered: both men and women require having proof of their ability to gratify each other's erotic desire. This general proposition might prove hard to substantiate, and it might call up objections of different kinds. One might claim, for instance, that: people do not care for the satisfaction of their partners, but only for their own. Or, it might be objected that men and women do not understand and react to sexual desire in the same way, and consequently, seeing their desire as identical (and reciprocal) is false. Obviously, we might also respond to the poem in this way and come up with similar objections. Its rhetorical force, however, makes such a response less likely. This strength is achieved through the repetitions on the phonological, syntactical, and semantic 
levels correlated with its repeated parallel framing in question and answer. Blake's poem is, like poems in general, a complex system that engenders emergent qualities, because the material and formal aspects of the text enhance the plausibility and force of the propositional content. Further, Blake's poem seems to imitate a preliterary genre that makes specific use of the question/answer-structure, namely the riddle.

To solve a riddle is to unveil a secret and, according to magical thinking, may mean the acquisition of great, sometimes superhuman, power (cf. Oedipus solving the riddle of the Sphinx). And solving a riddle is precisely what this poem pretends to do. Thus what with regard to its propositional content seems to be an assertion of a general state of affairs is, as regards its propositional attitude, a magical act, a conjuration to the effect that men and women desire each other's desire-as if stating the answer as a fact would make it one. Thus, the poem forcefully expresses an emotive attitude and a belief, namely the conviction that something, whose reality would be vitally important to most people, is in fact the case. In doing so, the focus has changed from what has been said about a (supposed) state of affairs in the world, i.e., from the represented to the text as an utterance to which the utterer is committed and of whose truth and significance he attempts to persuade his interlocutors.

Here we confront one of the perennial questions concerning literature, namely the question of which kind of knowledge literature embodies. Is literature a kind of knowledge sui generis, revealing states of affairs only accessible through it? Or is the cognitive content of literature related to doxa, to that which is commonly thought to be the case, or to that which ought to be the case? In my opinion literature is the latter, not the former. Most often literature neither creates nor is it instrumental in bringing about novel knowledge, be it theoretical, practical, historical, or technical. However, literature is about something else that, in my opinion, is even more important: it creates novel experiences, in the sense that it exemplifies ways in which the subject, or rather subjects do, could or should relate to each other and to the lifeworld. Knowledge is either knowing that something is, or is not, the case, or knowing how to do something. Knowledge is oriented either towards states of affairs or achievements. Experience, however, means counting in the subject, and consequently, experience means being emotionally involved with and responding to what confronts us. Further, experience is felt as synthetic and intuitive (although unconsciously it may be interpretive and analytic). Obviously, it will often become an object of reflection and interpretation (as here the experience of Blake's poem), but before that it is an event that occurs and matters to somebody.

\section{Literature and Science}

This is why it is questionable to claim that, for instance, literature and science are two specific forms in which the same object is given. Maybe it is more correct and fruitful to say that literature and science only on a very high level of abstraction can be said to treat the same object. They seem rather each to focus on a separate pole in the subject-object relationship. Experience, on my view, is related to the subject pole and knowledge to the object pole. Thus, it seems to be true that what is accessed through literature could not be accessed through science, it would disappear by the way in which science would approach it. 
However, what is expressed in literature is not unique. On the contrary, literature expresses everyday experience, except that it often is concentrated on peak moments or crises and rites of passage, and except that it may put into language something that would otherwise remain unsaid. Furthermore, the fact that it expresses common experiences is its strength.

It has further been argued that there are two modes of cognitive functioning "each providing distinctive ways of ordering experience." They are thought to be irreducible to one another, and operating according their own, different criteria of well-formedness:

One mode, the paradigmatic or logico-scientific one, attempts to fulfill the ideal of a formal, mathematical system of description and explanation. It employs categorization or conceptualization and the operations by which categories are established, instantiated, idealized and related to one another to form a system. [...] At gross level, the logico-scientific mode (I shall call it paradigmatic hereafter) deals in general causes, and their establishment, and make use procedures to assure verifiable reference and to test for empirical truth. Its language is regulated by requirements of consistency and noncontradiction.

$[\ldots]$

[...] the narrative mode leads instead to good stories, gripping drama, believable (though not necessarily "true") historical account. It deals with human or human-like intention and action and the vicissitudes and consequences that mark their course. (Bruner 1986: 12-13).

One might wish to qualify the claims of Bruner concerning certain points. For instance, literature, including narrative, is also different from the paradigmatic mode of thought by the double insistency, even obtrusiveness, of language within it. On the one hand, language as material quality becomes palpable, to use Jakobson's expression, on the other, the polysemy of words and phrases is explored (in other places Bruner recognizes this difference). Furthermore, literature certainly includes and makes use of arguments. Nevertheless, it uses them primarily rhetorically: the text is not created for the sake of the argument; the office of the argument is to attribute to the global effect of the text. Finally, it should be stressed that Bruner's description of the modes are, as he says himself, "platonic," it describes what the paradigmatic and the narrative modes ideally, but also typically, do; thus leaving room for their being mixed in concrete instances. ${ }^{6}$

Blake's poem illustrates the narrative-poetical, or mythical mode of thinking: like most literature, it does not procure new knowledge. On the contrary, most grown-ups know immediately what the matter is - and that it matters. And this is precisely the point. The relevance and importance, of Blake's poem lies in its integration of common experience and subjective and emotional engagement (here conjuring is supposed to bring about a wish-fulfillment) through the poetic expression. This is, as shown above, a major reason for New Criticism's idea that paraphrase is a heresy

\footnotetext{
${ }^{6}$ Bruner's distinction has been corroborated and developed by Merlin Donald who in the mental, and cerebral, development of man, i.e., cognitive evolution, distinguishes between the mythic and the theoretic culture, claiming that the mind of contemporary man is a hybrid and multi-layered (see Donald 1991).
} 
because it breaks up the interrelations and reciprocal reinforcement between the text levels. Hence, paraphrase is a heresy, not because (partial) translation of poetic texts is impossible - certainly it is not, but because the integrative nature of experiencing literature disappears, and thus its significance.

Thus the surplus-coding of the literary text does, at least in an important sense, call forth profound changes in the way it is experienced: That which outside literature would be stated as a hypothesis is, within it, stated as a fact; that which outside would be considered contingent, is inside it considered a necessity, and within it "proof" is furnished by the material and formal properties of uttering, rather than by the power of deductive and inductive arguments.

\section{Poetic Impacts}

Finally, we should ask whether there are ulterior reasons for the persuasiveness and emotional impact of poetic language? In fact I think that this may very well be the case. Listen to the following:

\section{TRANSCRIPT OF BABY TALK}

Sequence with Mother and Liam, 8 weeks

[p] Oh, what you say? You are going to tell me a story?

[pp] Tell me a story, then.

[ppp] Tell me a story. [BABY SOUND]

Really! Ah, that's a good story!

That was a good story, tell me more.

Tell me more?

Tell me more. Yes? [BABY SOUND]

Come on then.

$* * *$ [12 lines omitted] $* * *$

[sf] Ohhhh, [mf] big yawns!

Big yawns!

[p] Oh your ear's all squashed.

Your ear's squashed.

Have you got a squashed ear? Yes.

$* * *$ [17 lines omitted] $* * *$

Oh. Come on, then, tell me about it.

[sf] Ohhhh.

Ohhhh.

Lots of hiccups. [BABY SOUNDS]

Yes. [p] Lots and lots of hiccups. Um-hm. [RISING CONTOUR]

Another one!

Too much milk.

You've had too much milk.

You've had too much milk.

Yes.

Too much milk. (PAUSE)

[Softer] Too much milk. 
$* * *$ [3 lines omitted $] * * *$

$\mathrm{Oh}$ ! Oh! Oh, serious face.

What a serious face.

What a serious face.

(WHISPERS) Has he got tickly feet [acceler.]

Has he got tickly feet.

Has you got tickly feet?

Where's your tickly feet?

Where's your tickly feet?

Oh! You blowing bubbles?

[pp] You blowing bubbles,

With your tickly feet, oh, your tickly feet.

Sequence recorded in the laboratory of Prof. Colwyn Trevarthyn, University of

Edingburgh, U.K. Here quoted from Dissanayake 2001: 339)

This is baby talk, the way mothers worldwide ${ }^{7}$ talk to their babies the first six months of the infants' life. Ellen Dissanayake, who has written an important and excellent article on the implication for art of this phenomenon, has pointed out some of the features of this kind of talking. It is melodic and rhythmic; it uses stanza-like forms; repetition seems to be its master-device; it is hyperbolic; it uses elaboration, but it also simplifies; and it is directed towards eliciting and keeping the attention of the baby and to making it feel good.

Obviously the mother is saying something; she produces a string of meaningful sentences. The baby, however, has no clue whatsoever what she is talking about. However, this does not matter at all, because the baby does understand that it is the center of attention, that the most important person in its life is acting lovingly and with pleasure towards it. These positive feelings are communicated from mother to infant by means of poetic $\backslash$ rhetorical devices, namely simplification, repetition, exaggeration and elaboration. Dissanayake, stressing the early appearance of this kind of communication, calls aesthetic incunabula.

Given the fact that the first kind of communication between mother and infant makes an absolutely extensive use of rhetorical/poetic devices, it is, at least to me, no wonder that human beings enjoy and are being positively moved by these devices, whenever they encounter then later in life, and they encounter them all the time throughout life. One might even speculate, with Dissanayake, whether the infant's sensitivity to such patterning of speech "suggests that humans are born with natural (innate, universal) predispositions for aesthetic engagement." (ibid. 336).

Consequently, there are, I think, compelling reasons to hold that feelings are allimportant in literature because they are present in and elicited both by what is represented and by the way it is represented. Literature, being a part of the rhetorical use and structuring of language, is, in fact, designed to call forth feelings. It does not represent a general principle, but an individual, albeit most often typical, case, i.e. the handling by individual persons (characters and narrators) of specific situations and events, and how they emotionally respond to such challenges.

\footnotetext{
${ }^{7}$ Of course baby talk is also determined by the specific features of the language in question, but, nevertheless, very important features are the same independent of language structure.
} 
Open Access This article is distributed under the terms of the Creative Commons Attribution Noncommercial License which permits any noncommercial use, distribution, and reproduction in any medium, provided the original author(s) and source are credited.

\section{References}

Aristotle (1926).Art of Rhetoric (trans. J.H. Reese). Cambridge MASS/London: Harvard University Press/ Heinemann: Loeb.

Bruner, J. S. (1986). Actual minds, possible worlds. Cambridge MASS: Harvard University Press.

Brooks, C. (1947/1968). The well-wrought urn. London: Methuen: University Paperbacks.

Dissanayake, E. (2001). Aesthetic incunabula. Philosophy and Literature, 25, 335-346.

Donald, M. (1991). Origins of the modern mind. Three stages in the evolution of culture and cognition. Cambridge MASS: Harvard University Press.

Johansen, J. D. (2002). Literary discourse. A semiotic-pragmatic approach to literature (p. 489). Toronto: University of Toronto Press.

Lukács, G. (1963). Ästhetik I-II (Gesammelte Werke Band 11-12). Neuwid: Luchterhand Verlag.

Perelman, Ch, \& Olbrechts-Tyteca, L. (1969). The new rhetoric. Notre Dame: Notre Dame University Press.

Veivo, H., Ljungberg, C., \& Johansen, J. D. (Eds.). (2009). Redefining literary semiotics. Cambridge: Cambridge Scholars.

Wimsatt, W., \& Beardsley, M. (1954). The intentional fallacy. In W. K. Wimsatt (Ed.), The verbal icon: Studies in the meaning of poetry (pp. 3-18). Town: U of Kentucky Press.

Jørgen Dines Johansen (born 1943). Ph.d. from Copenhagen University in general and comparative literature 1970. Received the gold medal of Copenhagen University for a prize essay on Postwar Theories of the Novelle 1969 (published 1970). Professor of general and comparative literature at University of Southern Denmark since 1976. In 1999 he got prix mouton d'or for an article in Semiotica "A diagrammatic modeling of semiosis." In 2004 his book Literary Discourse. A Semiotic-Pragmatic Approach to Literature (University of Toronto Press 2002) received the Perkins-prize from The American Society for the Study of Narrative Literature. 